\title{
Diagnostic Utility of Fine Needle Aspiration Cytology of the Orbit: A 26 Year Retrospective Study of a Single Institution's Experience
}

\section{Mustafa Yousif ${ }^{1}$, Jing Lu ${ }^{1}$, Ariel Frost ${ }^{2}$, Rebecca Steele ${ }^{1}$ and Ziyan T Salih ${ }^{* 1}$}

${ }^{1}$ Department of Pathology, Wake Forest University School of Medicine, Winston-Salem, NC, USA

${ }^{2}$ Department of Otorhinolaryngology, Hospital of the University of Pennsylvania, Philadelphia, PA, USA

"Corresponding author: Ziyan T Salih, Department of Pathology, Wake Forest University School of Medicine, Winston-Salem, NC, USA, Tel: 6024231062; E-mail: zsalih@wakehealth.edu

Received date: November 14, 2018; Accepted date: November 19, 2018; Published date: November 23, 2018

Copyright: (c) 2018 Yousif M, et al. This is an open-access article distributed under the terms of the Creative Commons Attribution License, which permits unrestricted use, distribution, and reproduction in any medium, provided the original author and source are credited.

\section{Abstract}

Objectives: Diagnosing orbital tumors is challenging due to the intricate anatomy of the orbit and associated risks of surgical biopsy. Fine needle aspiration (FNA) of the orbit provides a less invasive alternative to surgical biopsy.

Study Design: The surgical pathology database was retrospectively searched and analyzed for orbital specimens obtained by fine needle aspiration at Wake Forest Baptist Medical Center between the years 1990 and 2016.

Results: Of the 62 specimens from 61 patients, 38 cases (38/62, 61.3\%) were malignant neoplasms, 9 cases $(9 / 62,14.5 \%)$ were benign lesions, and 15 cases $(15 / 62,24.2 \%)$ were unsatisfactory/non-diagnostic. The most common neoplastic diagnosis was hemato/lympho-proliferative processes $(33 / 38,86.8 \%$ of the malignant neoplastic lesions), predominantly non-Hodgkin's lymphoma (NHL) $(29 / 38,76.3 \%$ of the malignant neoplastic lesions). $19 \mathrm{NHL}$ cases $(65.5 \%$ of $\mathrm{NHL}$ cases) had been confirmed by subsequent flow cytometric analysis. FNA results from 12 cases had been compared with surgical biopsy diagnosis. The diagnostic accuracy was $11 / 12$ or $91.7 \%$.

Conclusions: FNA of the orbit is a relatively non-invasive and cost-effective method in diagnosing orbital tumors; it is especially valuable in identifying hematolymphoid malignancies in the orbit, mainly non-Hodgkin's lymphoma.

Keywords: Orbit; Fine needle aspiration; Non-Hodgkin's lymphoma; Malignancies

\section{Introduction}

Orbital tumors are rare and often referred to tertiary care specialized medical centers for management. The anatomy of the orbit is complex and invasive surgical biopsy raises the risk of globe rupture/ injury. These factors can make diagnosing orbital lesions challenging. As a result, there is limited familiarity with orbital specimens and the diagnostic differential they pose.

Fine needle aspiration (FNA) of the orbit with or without the use of imaging guidance (radiologic assistance) is a relatively non-invasive, well-accepted and reliable procedure that can aid in the initial stages of diagnosis. Herein, we review a single institution's experience with FNA of the orbit. Our study shows that FNA provides a cost-effective diagnostic approach to orbital tumor diagnosis, especially for nonHodgkin's lymphomas.

\section{Materials and Methods}

The surgical pathology database was retrospectively searched for orbital specimens obtained by fine needle aspiration at Wake Forest Baptist Medical Center between the years 1990 and 2016. Ultrasound or computed tomography (CT)-guided FNA were performed by a radiologist with a cytopathologist or a cytotechnologist physically present at the time of the procedure to assess sample adequacy, provide on site evaluation and triaging the obtained material. The aspirate smears were stained by modified Romanowski stain (Diff-Quik) and Papanicolaou stain. Syringes were rinsed with saline solution to prepare a cell block, or rinsed into flow media for flow cytometry analysis. A total of 62 specimens were identified and classified into three categories: neoplastic, non-neoplastic, and unsatisfactory/nondiagnostic.

\section{Results}

Of the 61 patients, 34 were female and 27 were male, with an age range of 3 months to 94 years (mean 63 years). There was only one pediatric patient. Evaluation of the fine needle aspiration cytology yielded the following diagnoses: 38 cases $(38 / 62,61.3 \%)$ were malignant neoplasms, 9 cases $(9 / 62,14.5 \%)$ were benign lesions, and 15 cases $(15 / 62,24.2 \%)$ were unsatisfactory/non-diagnostic.

The most common neoplastic diagnosis was hemato/lymphoproliferative processes (33/38 neoplastic cases, $86.8 \%)$, predominantly non-Hodgkin's lymphoma (NHL) (29/38, 76.3\%). 3 cases were plasmacytoma $(3 / 38,7.8 \%)$; and 1 hemato/lympho-proliferative case was diagnosed as atypical leukocytes favor benign $(1 / 38,2.6 \%)$ (Figure $1)$.

Of the 29 cases diagnosed as NHL, 7 cases were small lymphocytic lymphoma (SLL) (7/29), 5 cases were suspicious for lymphoma (5/29), 
Citation: Yousif M, Lu J, Frost A, Steele R, Salih ZT (2018) Diagnostic Utility of Fine Needle Aspiration Cytology of the Orbit: A 26 Year Retrospective Study of a Single Institution's Experience. J Cytol Histol 9: 525. doi:10.4172/2157-7099.1000525

Page 2 of 5

4 cases were follicular lymphoma (4/29), 4 cases were mantle cell lymphoma (4/29), one case was marginal zone lymphoma (1/29), and the other 8 cases were unclassified NHL (8/29) (Figure 2).

Papanicolaou stain and Diff-Quik stain were used for cytomorphologic analysis on aspirate smear slides. As shown in Figure 3, cases diagnosed with NHL demonstrated dis-cohesive, monotonous lymphocytic population which was characteristics of lymphoma. Flow cytometric analysis was utilized to confirm the diagnosis in the majority of NHL cases (19/29). 3 NHL cases were confirmed by immunohistochemical staining on surgically resected specimens $(3 / 29)$. One NHL case was confirmed by immunohistochemical staining on FNA cell block material (1/29).
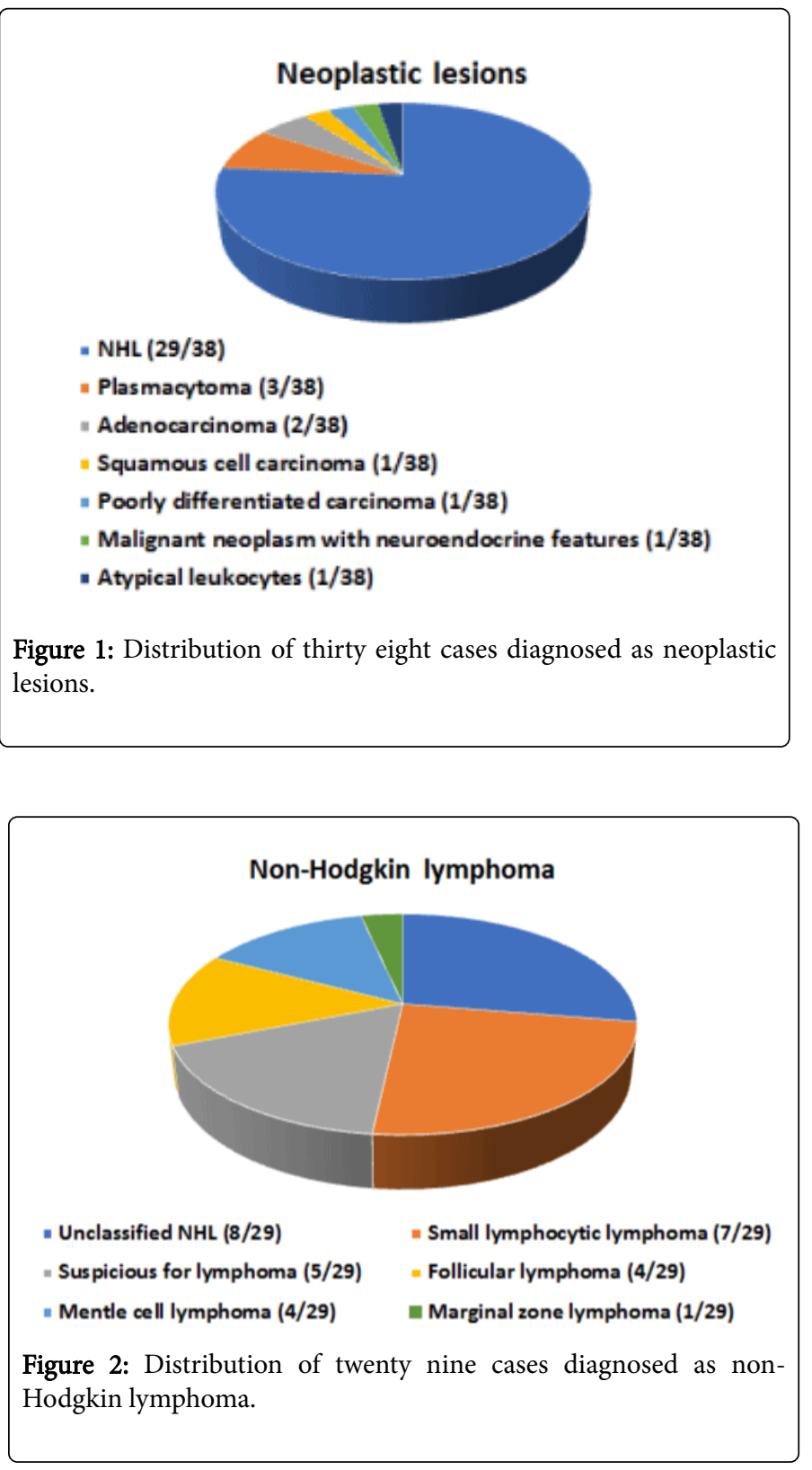

Figure 2: Distribution of twenty nine cases diagnosed as nonHodgkin lymphoma.

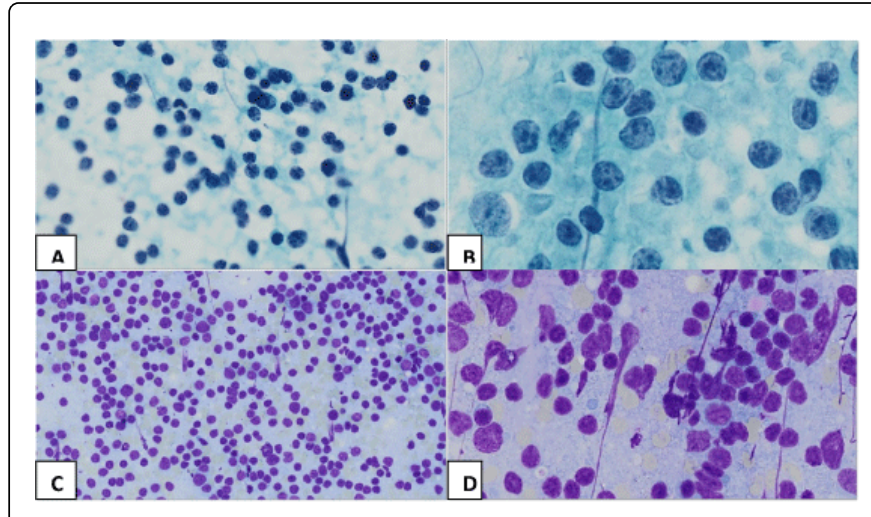

Figure 3: (A and B) Papanicolaou stain of small lymphocytic lymphoma (CLL/SLL) demonstrates a dis-cohesive, monotonous small lymphocytic population (Papanicolaou stain, original magnification A: 20x, B: 40x). (C and D) Modified Romanowski (Diff-Quik) stain of non-Hodgkin's lymphoma, NOS demonstrates a dis-cohesive, medium-sized lymphocytic population with lymphoglandular bodies in the background (Diff-Quick stain, original magnification C: 20x, D: 40x).
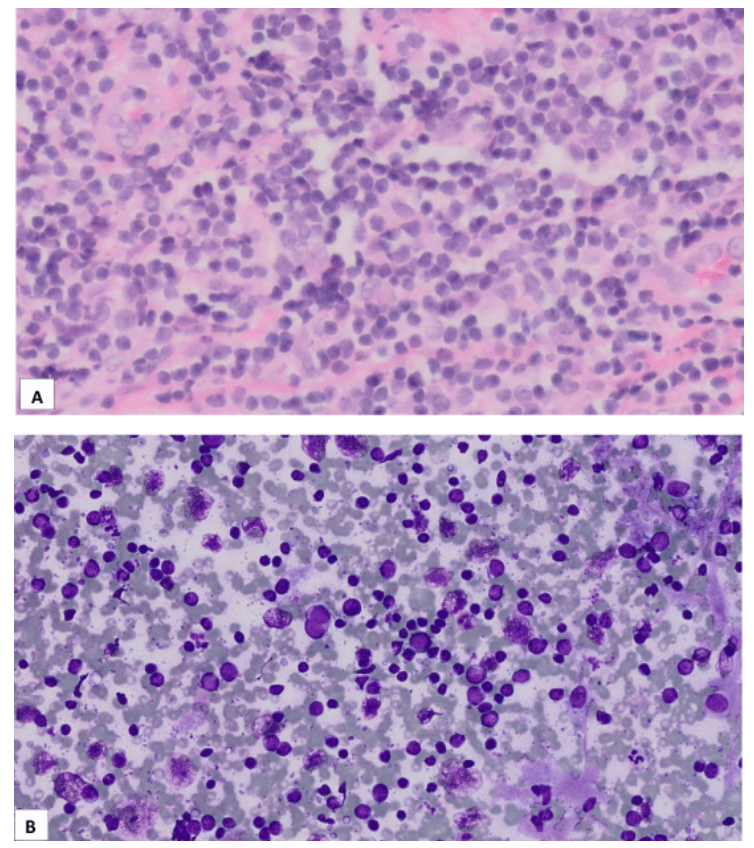

Figure 4: A typical lymphoid proliferation, favor benign. A, Histology shows a diffuse lymphocytic infiltrate composed of smallto medium-sized lymphocytes and scattered histiocytes. (Hematoxylin-eosin, original magnification 40x) B, FNA cytology shows a heterogenous population of small- to medium-sized lymphocytes (Diff-Quick stain, original magnification 20x).

There were 9 other neoplastic cases including plasmacytoma (3/38), adenocarcinoma (2/38), squamous cell carcinoma (1/38), poorly differentiated carcinoma (1/38), neoplasm with neuroendocrine features (1/38), and atypical leukocytes favor reactive (1/38) (Figure 1). 
Citation: Yousif M, Lu J, Frost A, Steele R, Salih ZT (2018) Diagnostic Utility of Fine Needle Aspiration Cytology of the Orbit: A 26 Year Retrospective Study of a Single Institution's Experience. J Cytol Histol 9: 525. doi:10.4172/2157-7099.1000525

Page 3 of 5

Most of the benign lesions were diagnosed as lymphoid infiltrate/ proliferation (4/9 benign cases). 4 benign cases underwent surgical resection and were all confirmed benign $(4 / 4,100 \%)$.

There were 15 unsatisfactory cases due to scant cellularity, crushing and drying artifacts, 11 of which were further diagnosed by surgical resection, including inflammatory infiltration (5/11), meningioma $(1 / 11)$, infantile myofibromatosis (1/11), amyloidosis (1/11), atypical fibroxanthoma (1/11), SFT (1/11), and B cell lymphoma (1/11).

In total, 23 cases including 11 cases with unsatisfactory FNA diagnosis underwent subsequent surgical excision/incision. Among the 12 cases with original satisfactory FNA diagnosis, 11 cases had a surgical excision/incision diagnosis concordant with the prior FNA results $(11 / 12,91.7 \%)$ (Table 1$)$.

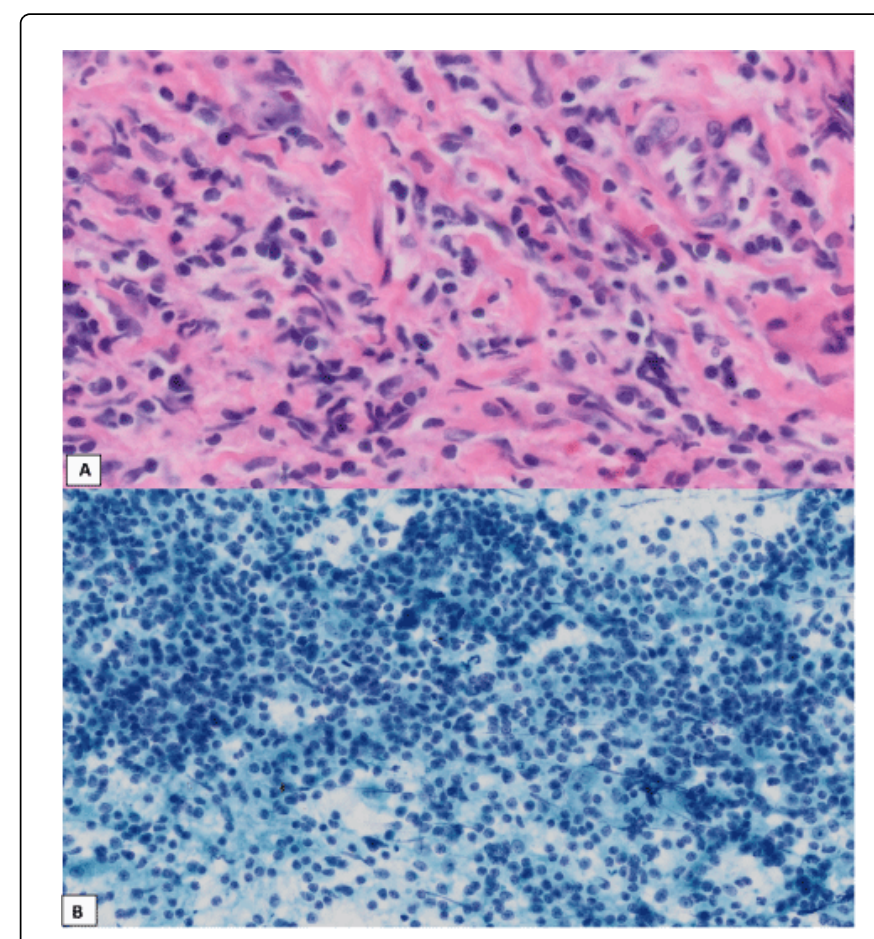

Figure 5: Large B-cell lymphoma. A, Histology shows an infiltrate of predominantly large lymphocytes (Hematoxylin-eosin, original magnification 40x) B, FNA cytology shows a hypercellular aspirate with a monomorphic population of large lymphocytes (Papanicolaou stain, original magnification 20x).

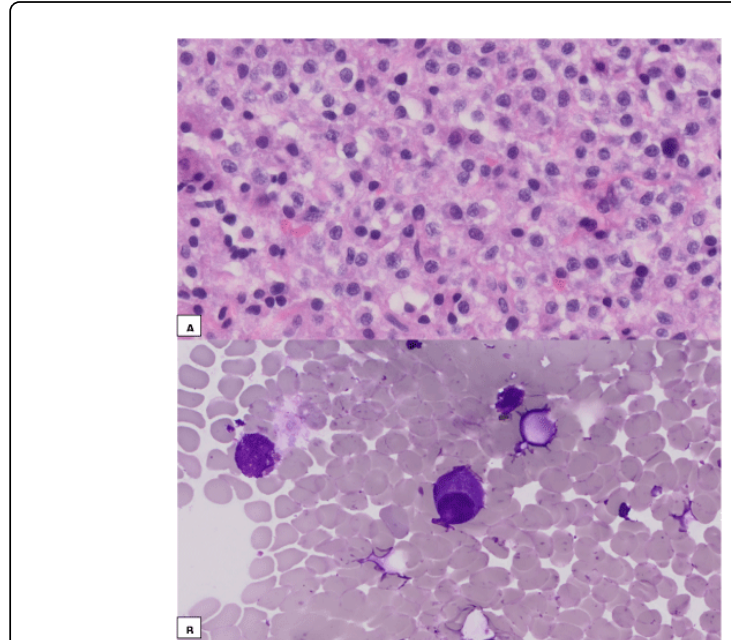

Figure 6: Plasmacytoma. A, Histology shows sheets of plasma cells with eosinophilic cytoplasm and round, eccentric nuclei (Hematoxylin-eosin, original magnification 40x) B, FNA cytology shows plasma cells with round, eccentric nuclei and perinuclear clearing (Diff-Quick stain, original magnification 60x).

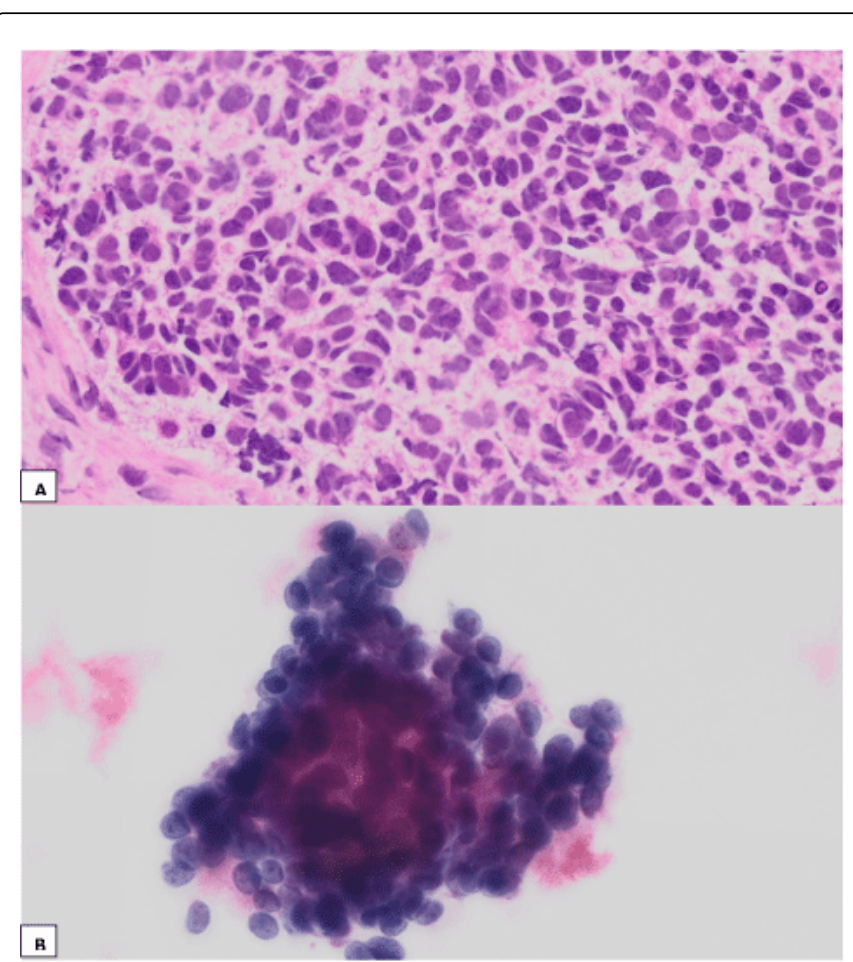

Figure 7: Poorly differentiated carcinoma. A, Histology shows nests of tumor cells with angulated, hyperchromatic nuclei and occasional prominent nucleoli. (Hematoxylin-eosin, original magnification 40x) B, FNA cytology shows cohesive clusters of tumor cells with scant cytoplasm, dark nuclei, and prominent nucleoli (Papanicolaou stain, original magnification 60x). 


\begin{tabular}{|c|c|c|c|c|c|c|}
\hline No. & Age & sex & Race & Site & FNA Diagnosis & Histology Diagnosis \\
\hline 1 & 66 & $\mathrm{~F}$ & W & orbit & Unsatisfactory for diagnosis & Chronic inflammation \\
\hline 2 & 55 & $\mathrm{~F}$ & W & orbit & Unsatisfactory for diagnosis & Inflammation (Inflammatory Pseudotumor) \\
\hline 3 & 40 & $\mathrm{~F}$ & W & orbit & Unsatisfactory for diagnosis & Meningioma \\
\hline 4 & 83 & $\mathrm{~F}$ & W & orbit & Atypical cells worrisome for malignancy & Invasive Squamous Cell Carcinoma \\
\hline 5 & 25 & M & W & orbit & Benign-Appearing Glandular Cells & Eosinophilic granuloma \\
\hline 6 & $3 m$ & M & W & orbit & Unsatisfactory for diagnosis & Infantile myofibromatosis \\
\hline 7 & 55 & $\mathrm{~F}$ & B & orbit & Unsatisfactory for diagnosis & Amyloidosis \\
\hline 8 & 40 & $\mathrm{~F}$ & W & orbit & Atypical cells worrisome for neoplasm & Poorly differentiated adenocarcinoma. \\
\hline 9 & 76 & M & W & orbit & Unsatisfactory for diagnosis & Atypical Fibroxanthoma \\
\hline 10 & 74 & $\mathrm{~F}$ & W & orbit & $\begin{array}{l}\text { Atypical lymphoid proliferation suspicious for } \\
\text { lymphoma. }\end{array}$ & $\begin{array}{l}\text { Malignant lymphoma, low grade B-cell, follicular } \\
\text { type. }\end{array}$ \\
\hline 11 & 42 & $\mathrm{~F}$ & W & orbit & Suspicious for neoplasm & Poorly differentiated carcinoma. \\
\hline 12 & 94 & M & W & orbit & $\begin{array}{l}\text { Atypical lymphoid proliferation suspicious for B-cell } \\
\text { lymphoma. }\end{array}$ & $\begin{array}{l}\text { Malignant non-Hodgkin's lymphoma, large cell } \\
\text { type, B-cell variant }\end{array}$ \\
\hline 13 & 46 & M & W & orbit & $\begin{array}{l}\text { Atypical lymphoid proliferation suspicious for } \\
\text { lymphoma. }\end{array}$ & Sclerosing orbital pseudotumor (Benign) \\
\hline 14 & 41 & M & W & orbit & Negative for malignancy & Cavernous hemangioma. \\
\hline 15 & 55 & M & W & orbit & Unsatisfactory for diagnosis & Reactive lymphoid infiltrate \\
\hline 16 & 71 & M & W & orbit & Unsatisfactory for diagnosis & Solitary fibrous tumor \\
\hline 17 & 87 & $\mathrm{~F}$ & W & orbit & Unsatisfactory for diagnosis & Intravascular B cell Lymphoma \\
\hline 18 & 53 & M & W & orbit & Scattered plasmacytoid cells & Plasmacytoma \\
\hline 19 & 59 & $\mathrm{~F}$ & W & orbit & Unsatisfactory for diagnosis & $\begin{array}{l}\text { Inflammation } \\
\text { Mixed inflammatory infiltration }\end{array}$ \\
\hline 20 & 34 & $\mathrm{~F}$ & $B$ & orbit & Unsatisfactory for diagnosis & Chronic inflammation \\
\hline 21 & 90 & M & W & orbit & Atypical cellular proliferation suspicious for lymphoma. & Diffuse large B-cell lymphoma \\
\hline 22 & 65 & M & B & orbit & Lymphoma, not otherwise specified & Large B-cell lymphoma \\
\hline 23 & 32 & $\mathrm{~F}$ & B & orbit & Atypical lymphoid proliferation, favor benign & $\begin{array}{l}\text { Reactive lymphocytic proliferation with germinal } \\
\text { center formation }\end{array}$ \\
\hline
\end{tabular}

Table 1: 23 cases including 11 cases with unsatisfactory FNA diagnosis underwent subsequent surgical excision/incision.

\section{Discussion and Conclusion}

Orbital tumor diagnosis has long been a challenging task for ophthalmologists. A surgical excisional or incisional biopsy carries significant risks and complications. FNA has been a reliable approach in the diagnosis of lesions from multiple organs including lung, thyroid gland, lymph nodes, pancreas, and salivary gland since the 1960s. In 1975, Dr. Schyberg first introduced FNA to orbital tumor diagnosis [1]. Although the discrepancy about the application of FNA to orbital tumors still exists [2-4], a growing number of institutions are showing interest in applying this technique as an alternative to surgical biopsy [5-10].

Our current retrospective study analyzed data collected from 61 patients (62 cases) who underwent FNA in our institution between the years 1990 and 2016. Of the 62 cases, 15 cases were unsatisfactory/ non-diagnostic, so the positive identification rate was (47/62, 75.8\%). More than half of the cases were malignant neoplasms, the majority of which were non-Hodgkin's Lymphomas. Flow cytometry has been proven to be a rapid and virtually diagnostic method for nonHodgkin's lymphoma [11]. Our study shows FNA provides adequate materials for flow cytometry to make a definitive diagnosis in $(19 / 29$, 65.5\%) NHL cases.

We compared the FNA results with surgical biopsy diagnosis in 12 cases with adequate materials. The diagnostic accuracy was 11/12, or $91.7 \%$, which was comparable with other reports [6-10]. On the benign end of the spectrum, a reactive lymphoid proliferation specimen showed a heterogenous population of small to medium-sized 
Citation: Yousif M, Lu J, Frost A, Steele R, Salih ZT (2018) Diagnostic Utility of Fine Needle Aspiration Cytology of the Orbit: A 26 Year Retrospective Study of a Single Institution's Experience. J Cytol Histol 9: 525. doi:10.4172/2157-7099.1000525

Page 5 of 5

lymphocytes on both cytology and histology, with germinal center formation seen on histology and a background of lympho-glandular bodies on cytology (Figure 4). Both cytology and surgical specimens for a case of large B-cell lymphoma showed an infiltrate of large, atypical lymphocytes, with prominent nucleoli and irregular nuclear contours (Figure 5). An FNA of an orbital mass in a patient with a prior history of plasma cell neoplasm showed scattered plasma cells; surgical biopsy confirmed the diagnosis of plasmacytoma, showing sheets of plasma cells which were lambda light chain restricted by in situ hybridization (Figure 6). Concordance was also seen in the diagnosis of non-hematopoietic neoplasms. A poorly differentiated carcinoma showed nests of tumor cells on histology and tight clusters of tumor cells on cytology; in both specimens the malignant cells had a basaloid appearance, with high nuclear: cytoplasmic ratio and dense, hyperchromatic nuclear chromatin (Figure 7).

Although surgical biopsy is considered the "gold standard" in diagnosing orbit tumors, it also carries significant risks and complications, as well as time and labor cost. Thus, FNA provides ophthalmologists and pathologists an ideal diagnostic approach for unresectable or high-risk orbital tumors.

Overall, this study demonstrates FNA of the orbit is a relatively noninvasive and cost-effective method in diagnosing orbital tumors; it is especially valuable in identifying hematolymphoid malignancy in the orbit, such as non-Hodgkin's lymphoma.

\section{References}

1. Schyberg E (1975) Fine needle biopsy of orbital tumors. Acta Opthalmol Suppl 125: 11 .
2. Krohel GB, Tobin DR, Chavis RM (1985) Inaccuracy of fine needle aspiration biopsy. Ophthalmology 92: 666-670.

3. Char DH, Cole TB, Miller TR (2012) False negative orbital fine needle biopsy. Orbit 31: 194-196.

4. Liu D (1985) Complications of fine needle aspiration biopsy of the orbit. Ophthalmology 92: 1768-1771.

5. Agrawal P, Dey P, Lal A (2013) Fine-needle aspiration cytology of orbital and eyelid lesions. Diagnostic Cytopathology 41: 1000-1011.

6. Nag D, Bandyopadhyay R, Mondal SK, Nandi A, Bhaduri G, et al. (2014) The role of fine needle aspiration cytology in the diagnosis of orbital lesions. Clin Cancer Investig J 3: 21-25.

7. Nair, Lekhakrishnan, Sankar S (2014) Role of Fine Needle Aspiration Cytology in the Diagnosis of Orbital Masses: A Study of 41 Cases. Journal of Cytology 31: 87-90.

8. Wiktorin AC, Dafgard Kopp EM, Tani E, Soderen B, Allen RC (2016) Fine-Needle Aspiration Biopsy in Orbital Lesions: A Retrospective Study of 225 Cases. Am J Ophthalmol 166: 37-42.

9. Zeppa P, Tranfa F, Errico ME, Troncone G, Fulciniti F, et al. (1997) Fine needle aspiration (FNA) biopsy of orbital masses: a critical review of 51 cases. Cytopathology 8: 366-372.

10. Tijl JW, Koornneef L (1991) Fine needle aspiration biopsy in orbital tumours. Br J Ophthalmol 75: 491-492.

11. Morse EE, Yamase HT, Greenberg BR, Sporn J, Harshaw SA, et al. (1994) The role of flow cytometry in the diagnosis of lymphoma: a critical analysis. Ann Clin Lab Sci 24: 6-11. 